\title{
3.1. SECULAR VARIATION OF LONGITUDE AND RELATED PROBLEMS
}

\author{
M. TORAO, S. OKazAKI, and S. FUJII \\ (Tokyo Astronomical Observatory, Japan)
}

\begin{abstract}
The secular variations in longitude differences among several observatories were determined, but it is hard to consider that these results are literally due to continental drift. The large standard deviations of the data of longitude differences show the existence of external systematic errors in time observations.

\section{RÉSUMÉ}

Des variations séculaires des différences de longitudes entre plusieurs observatoires ont été trouvées; mais il est difficile de les considérer comme réellement dues à des dérives continentales. Les grands écarts-types sur les différences de longitudes montrent l'existence d'erreurs systématiques externes dans les observations de l'heure.
\end{abstract}

\section{Introduction}

We have analyzed the time observations of various observatories and have derived relative variations of longitude. The observatories and their combinations are designated as follows:

\begin{tabular}{|c|c|c|c|}
\hline G & Greenwich & & Washington \\
\hline $\mathrm{H}$ & Hamburg Hydrographic & $\mathbf{R}$ & Richmond \\
\hline $\mathrm{Pa}$ & Paris & BAg & Buenos-Aires Geodetic \\
\hline $\mathrm{Pt}$ & Potsdam Geodetic & BAn & Buenos-Aires Naval \\
\hline $\mathrm{U}$ & Uccle & To & Tokyo \\
\hline $\mathrm{O}$ & Ottawa & $\mathrm{Mz}$ & Mizusawa \\
\hline
\end{tabular}

The effect of polar motion was removed by using the coordinates of the instantaneous pole referred to a fixed pole, the mean pole from $1900 \cdot 0$ to $1906 \cdot 0$. Longitudes are positive to the west.

\section{Tendency for Long-Period Variations}

The summarized results from time observations for 30 years, 1933-62, for several combinations of observatories are shown in Table 1 and Figure 1. 
Table 1

Secular variations of longitude, in $\mathrm{ms} / \mathrm{yr}$, from 30 years data

Sec. Var. m.e.

$\begin{array}{crr}\text { To-W } & +1.05 & \pm 0.19 \\ \text { To-BAg } & +1.51 & .35 \\ \text { To-E5 } & +0.04 & .19 \\ \text { W }_{2}-E_{5} & -1.26 & .17 \\ \text { BAg-E5 } & -1.11 & .29 \\ \text { W }_{2}-\text { BAg } & -0.15 & .33\end{array}$

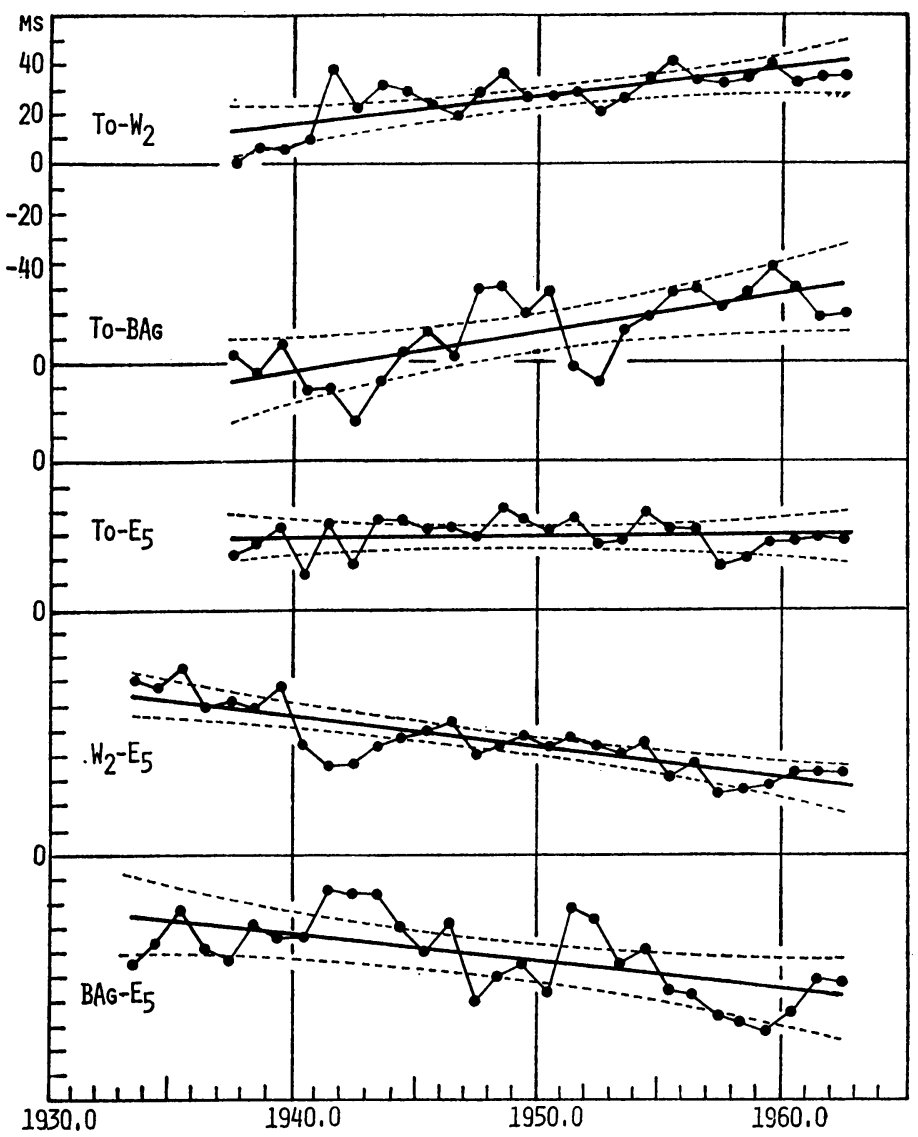

FIG. 1. Secular variation of the difference in longitude; result (I). Vertical ordinate shows relative difference in longitude.

\section{Solution for Short Intervals}

When we divided the data into two parts, (a) and (b), before and after 1950.0, different results were obtained, as shown in Table 2 and Figure 2. 
Table 2

Secular variations of longitude for short intervals

(a)

1933-49 (b)

1950-62 (c)

1956.8-1965.9

$-1.64 \pm 0.24$

$-0.39 \quad .45^{*}$

$-0.48 \quad .35$

$+1.23 \quad .29$

$-0.09 \quad .49 *$

$+1.32 \quad .46^{*}$

$\mathrm{W}_{2}-\mathrm{BAg}$

$-0.46$

.62

$-1.38$

.51

$-2.22 \quad 1.06$

$-1.30 \quad .86$

$+0.84 \quad .83$

* BA2. $+1937-49$.

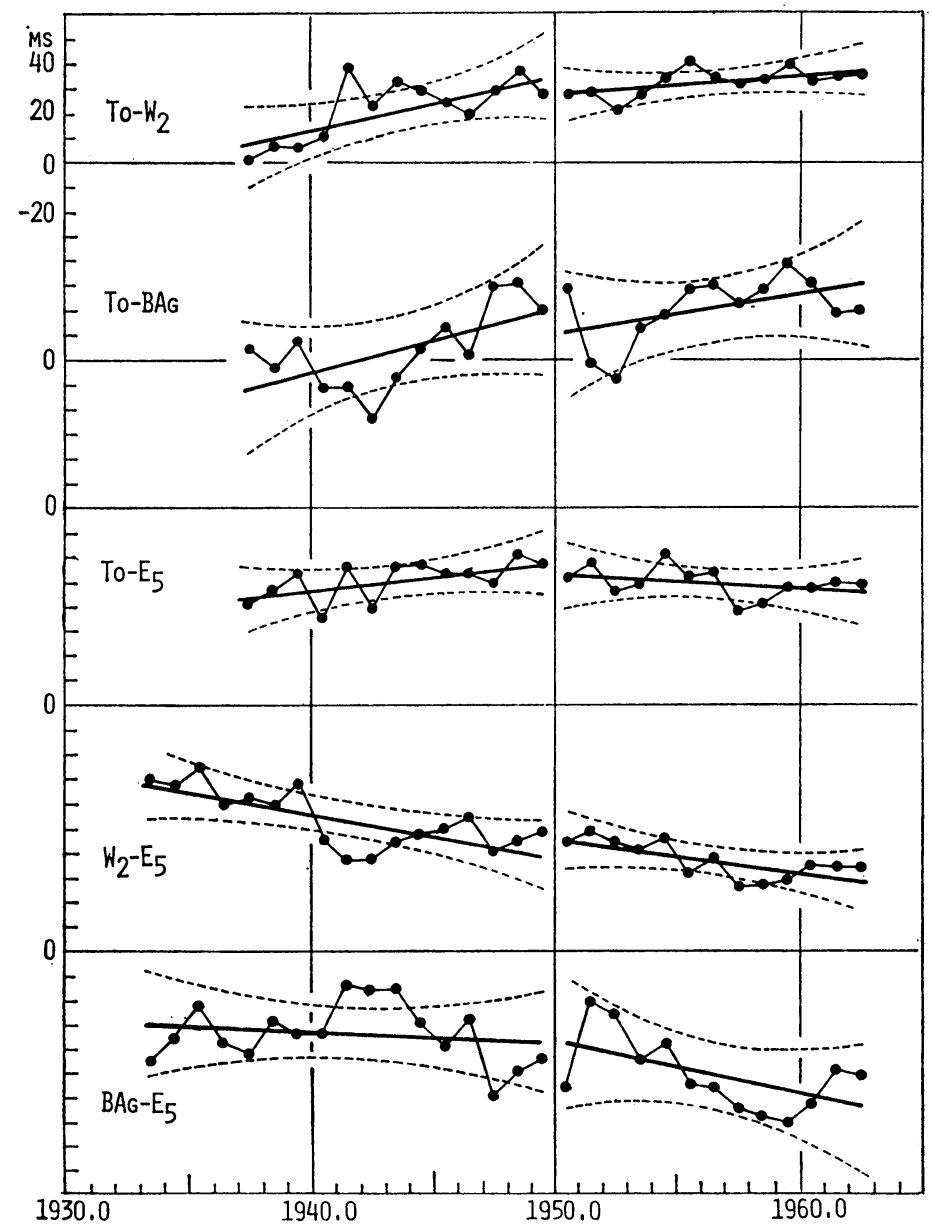

FIG. 2. Secular variation of the difference in longitude; results (a) and (b). 


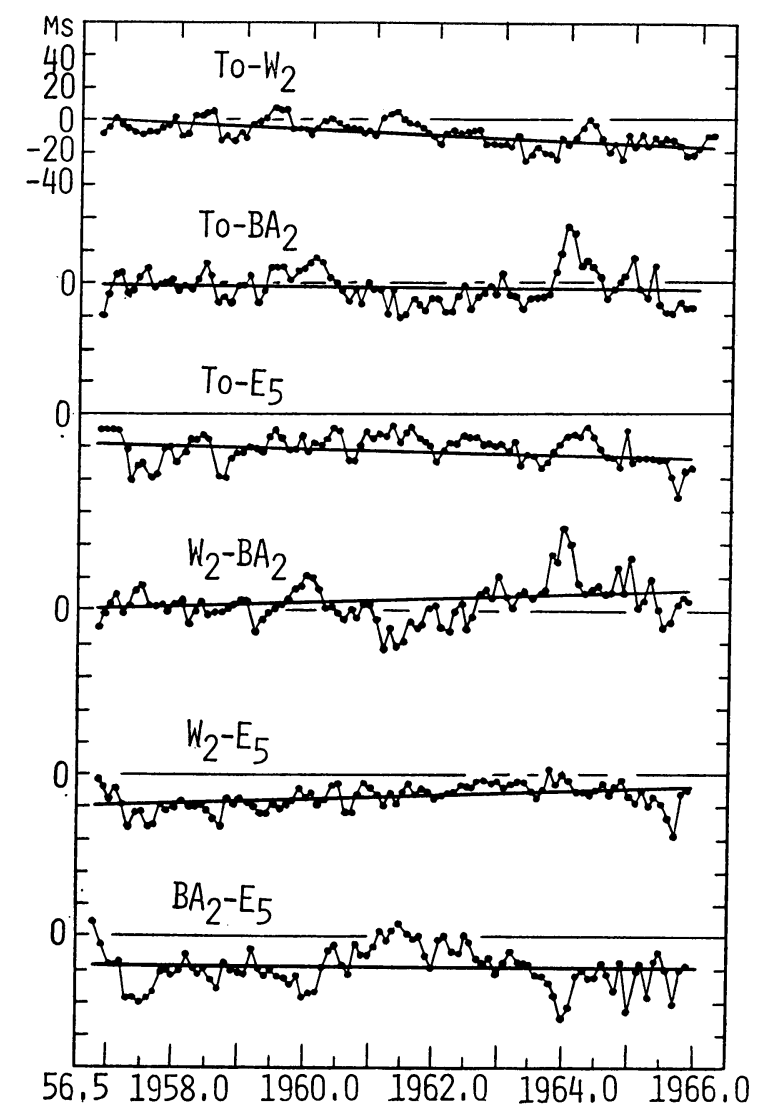

FIG. 3. Secular variation of the difference in longitude; result (c).

\section{Table 3}

Secular variations of longitude between nearby observatories, from recent data, 1956.8-1965.5

Sec. Var.

$\begin{array}{llr}\text { G-Pa } & -1.19 & \pm 0.41 \\ \text { G-H } & +0.57^{*} & .58 \\ \text { G-Pt } & -1.37 & .48 \\ \text { G-U } & +3.45 & .73 \\ \text { G-E5 } & +0.32 & .29 \\ \text { W-Rc } & +0.27 & .33 \\ \text { W2-O } & +1.73^{*} & .41 \\ \text { To-Mz } & -0.07^{* *} & .47 \\ \text { BAn-BAg } & -2.60 & .66\end{array}$

* After 1960.5.

**After 1958.1. 
We can use the atomic time scale from the end of 1956, so we reduced the results in terms of A.1, which is maintained by the Naval Observatory, Washington. We determined the secular variations of longitude differences for the recent 11-year interval, 1956.8-1965.9. The results are shown as (c) in Table 2 and Figure 3. There are large discrepancies between the results (a), (b), (c), and those obtained in Section 2.

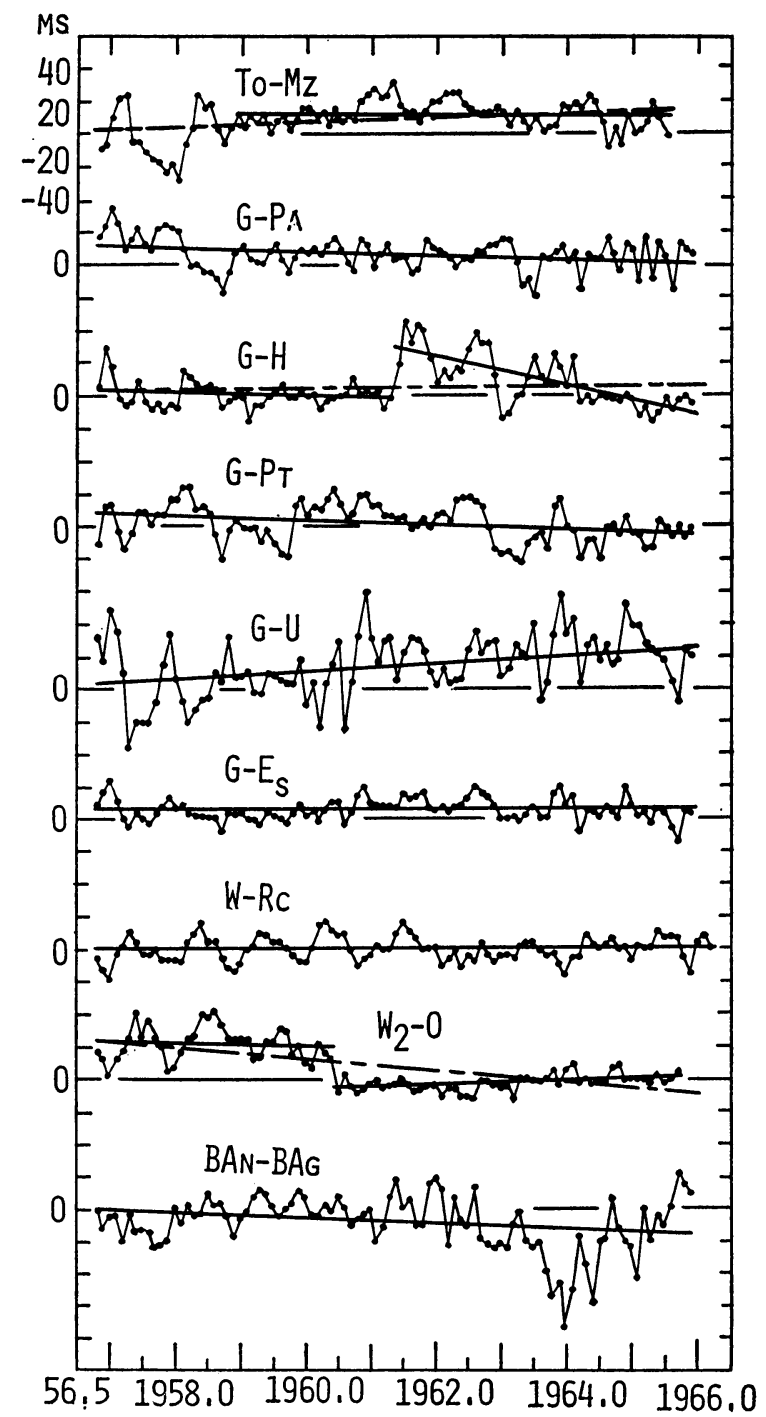

Fig. 4. Secular variation of the difference in longitude between nearby observatories. 


\section{Table 4}

Variations in longitude relative to mean observatory and standard deviations, 1956. 8-1965.5

\begin{tabular}{|c|c|c|c|c|c|}
\hline \multirow[b]{2}{*}{ To } & \multicolumn{2}{|c|}{$a(m s)$} & \multicolumn{2}{|c|}{$\mathrm{b}(\mathrm{ms} / \mathrm{y})$} & \multirow{2}{*}{$\begin{array}{c}\mathrm{s} \cdot \mathrm{d} \cdot(\mathrm{ms}) \\
\pm 5 \cdot 7\end{array}$} \\
\hline & $-8 \cdot 9$ & \pm 0.7 & -0.61 & \pm 0.24 & \\
\hline Mz & $-16 \cdot 1$ & 1.1 & $\begin{array}{c}-1.96 \\
(-0.54)^{*}\end{array}$ & .38 & $9 \cdot 1$ \\
\hline G & $+17 \cdot 1$ & 0.6 & -0.33 & $\cdot 22$ & $5 \cdot 2$ \\
\hline $\mathrm{Pa}$ & +9.5 & 1.0 & +0.86 & .36 & $8 \cdot 7$ \\
\hline $\mathbf{H}$ & $+12 \cdot 7$ & 1.5 & -0.91 & .52 & 12.5 \\
\hline $\mathbf{P t}$ & +14.0 & 1.1 & +1.03 & .40 & $9 \cdot 6$ \\
\hline U & +6.8 & 1.8 & $-3 \cdot 78$ & .65 & $15 \cdot 4$ \\
\hline W & $-3 \cdot 5$ & 0.5 & $+1 \cdot 12$ & $\cdot 18$ & 4.4 \\
\hline Rc & $-3 \cdot 2$ & 0.8 & +0.86 & .29 & $6 \cdot 9$ \\
\hline O & $-15 \cdot 8$ & 1.2 & $\begin{array}{c}+4.86 \\
(-0.61)^{* *}\end{array}$ & .42 & $9 \cdot 9$ \\
\hline BAg & -3.4 & 1.0 & +0.73 & .37 & $8 \cdot 7$ \\
\hline BAn & -9.9 & 1.7 & -1.87 & $\cdot 63$ & $14 \cdot 8$ \\
\hline
\end{tabular}

\section{Longitude Differences between Nearby Observatories}

Using recent time observations, the secular variations of longitudes between several pairs of nearby observatories were determined. The results are shown in Table 3 and Figure 4.

\section{Separate Results for Each Observatory}

From the recent data (c) in Section 3, we determined the standard deviation of a longitude determination relative to the mean longitude of 12 observatories for each 0.1 year interval, using the residuals:

$$
r_{i}=\left[\text { U.T. } 1_{i}-\text { U.T. } 1_{m}\right]-\left[a_{i}+b_{i}(t-1960 \cdot 0)\right],
$$

where U.T. $1_{m}$ is the mean U.T. $1_{i}$. The results are given in Table 4.

\section{Discussion and Conclusions}

The secular variations of longitude differences for various combinations of observatories as derived from long intervals seem to be significant, considering their mean errors. However, when we divide the data into two periods, very different results occur. The same situation appears for results from the recent, precise time observations. 
Regarding these circumstances, it is hard to consider that the observed secular variations of longitudes are due to continental drift. The large variations appearing for some pairs of nearby observatories lead to the same conclusion.

The external systematic error may be fairly large in the time observations. Because of this, the standard deviations shown in Section 5 are larger than those estimated from the internal accuracies of the recent observations. We have used in this study data published formally by each observatory. However, systematic effects introduced by changes in instruments or locations and by different star catalogues may not have been completely removed. The residual effects may be fairly large, as shown by Table 4 and Figure 4.

Unification of the systems of star places and proper motions of time and latitude stars is urgently needed. Studies of the effects of meteorological conditions are also important.

With the present accuracies, as shown in Section 3, about 20 or more years are needed for determining the secular variations of longitude within an accuracy of $\pm 0.1 \mathrm{~ms} / \mathrm{yr}$.

The general conclusion of the present paper is that there have been fairly large systematic errors in time observation so that the apparent secular changes in longitudes cannot be due to continental drift literally. 